\title{
FORCED LABOR OF A LAWYER: THE INEVITABILITY OF A CONFLICT IN A LENGTHY CRIMINAL TRIAL
}

\author{
Vasiliy A. Shavin \\ Lobachevsky State University of Nizhny Novgorod, Nizhny Novgorod, Russian Federation; \\ Chamber of Lawyers of the Nizhny Novgorod Region, Nizhny Novgorod, Russian Federation
}

Introduction: the paper raises the issue of forced labor in the legal profession, which, in the author's opinion, has several manifestations in the legal profession of modern Russia, in connection with which the aim is to conduct the study of the Russian and international legislation and the practice of its application according to the stated subject. Methods: the methodological framework for the research is a set of methods of scientific knowledge, among which the main ones are the method of analysis and synthesis and the comparative law method. Results: the author considers in detail the raised problem in the context of the national and international law. The conclusions are drawn and the variant of the solution to the existing legislative gap is offered. Conclusions: the problem of forced labor of a lawyer exists both in our country and abroad. Russia has not developed the specific legal mechanisms to strike a balance between the interests of all stakeholders: the principal, the lawyer, the state, the law corporation. In general, the work of a lawyer without a fee or with a significantly lower fee cannot be considered forced or compulsory work, since the lawyer knew about this possibility in advance and agreed to it. However, such work should deprive the lawyer of the opportunity to perform paid work, should not require the lawyer to spend extra time, effort, and money. Otherwise it would be a violation of Article 4 of the European Convention for the Protection of Human Rights and Fundamental Freedoms. Similar developments of the European Court and the US courts should be used in Russia to develop its own rules.

Key words: forced labor, lawyer, legal profession, termination of agreement on rendering legal assistance, fee, failure to pay a fee.

Citation. Shavin V.A. Forced Labor of a Lawyer: the Inevitability of a Conflict in a Lengthy Criminal Trial. Legal Concept, 2019, vol. 18, no. 1, pp. 57-62. (in Russian). DOI: https://doi.org/10.15688/lc.jvolsu.2019.1.7

\section{ПРИНУДИТЕЛЬНЫЙ ТРУД АДВОКАТА: НЕИЗБЕЖНОСТЬ КОНФЛИКТА В ДЛИТЕЛЬНОМ УГОЛОВНОМ ПРОЦЕССЕ}

\section{Василий Анатольевич Шавин}

Нижегородский государственный университет им. Н.И. Лобачевского, г. Нижний Новгород, Российская Федерация; Палата адвокатов Нижегородской области, г. Нижний Новгород, Российская Федерация

Введение: в статье поднят вопрос о принудительном труде в адвокатуре, который, на взгляд автора, имеет несколько воплощений в адвокатской деятельности современной России. Цель: провести исследование российского и международного законодательства и практики его применения по заявленной тематике. Методы: методологическую основу исследования составляет совокупность методов научного познания, среди которых основными являются метод анализа и синтеза и сравнительно-правовой метод. Результаты: автором подробно рассмотрена поднятая проблема с точки зрения национального и международного права. Сделаны выводы и предложен вариант выхода из существующего законодательного пробела. Выводы: проблема принудительного труда адвоката существует как в нашей стране, так и за рубежом. В России не выработаны конкретные правовые механизмы, позволяющие соблюсти баланс между интересами всех заинтересованных сторон: доверителя, адвоката, государства, адвокатской корпорации. В целом работу адвоката 
без гонорара или со значительно меньшим гонораром нельзя считать принудительным или обязательным трудом, поскольку адвокат заранее знал о такой возможности и дал на это согласие. Однако такая работа не должна лишать адвоката возможности выполнять оплачиваемую работу, не должна требовать от адвоката чрезмерных затрат времени, усилий, денежных средств. Иное будет являться нарушением ст. 4 Европейской конвенции о защите прав человека и основных свобод. Подобные наработки Европейского суда и судов США стоит использовать и в России для формирования собственных норм.

Ключевые слова: принудительный труд, адвокат, адвокатура, расторжение соглашения об оказании юридической помощи, гонорар, невыплата гонорара.

Цитирование. Шавин В. А. Принудительный труд адвоката: неизбежностьконфликта в длительном уголовном процессе // Legal Concept = Правовая парадигма. - 2019. - T. 18, № 1. - C. 57-62. - DOI: https://doi.org/ 10.15688/lc.jvolsu.2019.1.7

\section{Постановка проблемы}

На первый взгляд, тема статьи выглядит противоречивой: как принудительный труд можно связать с адвокатской деятельностью? Ведь принуждение работать - это проблема наиболее бедных слоев населения, к которым в массовом сознании адвокаты не относятся. Однако на самом деле в практической деятельности адвокатов, причем не только российских, этот вопрос в той или степени, в том или ином виде стоит на повестке дня. В ряде европейских государств уже найдены некоторые выходы из подобных ситуаций, в России же они только начинают обсуждаться в адвокатской среде. Указанную тематику в одном из ее аспектов - защите при неоплате гонорара - подхватила Адвокатская газета - печатный орган Федеральной палаты адвокатов РФ (далее также ФПА, Федеральная палата адвокатов) ${ }^{1}$ и издания региональных палат [2; 4].

Повторюсь, подобная постановка вопроса нестандартна и уже вызвала неприятие в адвокатском руководстве. Так, А.А. Орлов, вице-президент Адвокатской палаты Московской области, заместитель Председателя Комиссии ФПА РФ по этике и стандартам (далее также - КЭС $)^{2}$, заявил, что «аргумент [о принудительном труде] абсолютно непроходной, что у нас это рабский труд, принудительный труд адвоката и попытка зайти через эту сторону тоже не жизнеспособна» ${ }^{3}$.

Принудительный труд в адвокатуре связан с наличием у этого института публичной функции, что превращает адвокатуру в частно-публичную корпорацию. Именно государство, вмешиваясь в отношения между адвокатом и его доверителем, а также во внут- ренние дела адвокатуры, создает условия для появления недобровольного труда адвоката.

\section{Анализ российского законодательства}

Согласно п. 1 ст. 1 Федерального закона от 31 мая 2002 г. № 63-Ф3 «Об адвокатской деятельности и адвокатуре в Российской Федерации» (далее - Закон об адвокатуре) адвокатской деятельностью является квалифицированная юридическая помощь, оказываемая на профессиональной основе лицами, получившими статус адвоката в порядке, установленном этим законом, доверителям в целях защиты их прав, свобод и интересов, а также обеспечения доступа к правосудию. Адвокатская деятельность осуществляется на основе соглашения между адвокатом и доверителем. Адвокат осуществляет свою деятельность в адвокатских образованиях: кабинет, коллегия, бюро и юридическая консультация. Адвокатский кабинет - это форма индивидуального осуществления адвокатской деятельности; остальные три - некоммерческие организации, основанные на членстве.

Таким образом, адвокат не состоит в трудовых отношениях ни с доверителем, ни с адвокатским образованием. Поэтому трудовое законодательство на адвокатов при осуществлении адвокатской деятельности не распространяется ${ }^{4}$.

Запрет же принудительного труда разрабатывается прежде всего и наиболее полно именно трудовым правом. В ст. 4 Трудового кодекса РФ дано понятие этого термина и расшифрованы виды работ, которые относятся и не относятся к принудительному труду.

Межу тем запрет принудительного труда записан в Конституции РФ (ч. 2 ст. 37) и 
B.А. Шавин. Принудительный труд адвоката: неизбежность конфликта в длительном уголовном процессе

является межотраслевым принципом, который может применяться не только в трудовых, но и в иных видах отношений, где фигурирует такой феномен, как труд человека. Ясно, что труд опосредуется не только трудовым, но и иными отраслями права, как минимум гражданским (договоры подряда, оказания услуг, агентский договор, поручение и др.) и административным (прохождение государственной, муниципальной и военной службы).

Конституционный суд РФ уже применял ч. 2 ст. 37 Конституции РФ к отношениям по прохождению государственной гражданской службы в качестве помощника судьи ${ }^{5}$, по прохождению военной службы ${ }^{6}$, к отношениям по применению административного наказания в виде обязательных работ ${ }^{7}$. Однажды использовал это конституционное положение Конституционный суд РФ и при рассмотрении вопросов профессиональной деятельности адвоката ${ }^{8}$.

Следовательно, можно сделать вывод о том, что понятия «принудительный труд» и «адвокатская деятельность» сопрягаются, поскольку к профессиональной деятельности адвоката применимо понятие «труд», несмотря на отсутствие трудовых отношений.

В каких же ситуациях в адвокатской деятельности может возникать элемент принуждения?

Национальное законодательство понимает принудительный труд как выполнение работы под угрозой применения какого-либо наказания (насильственного воздействия) (ч. 2 ст. 4 Трудового кодекса РФ). Исходя из этого, я выделил две такие ситуации.

Первая связана с запретом адвокату отказаться от принятой на себя защиты (подп. 6 п. 4 ст. 6 Закона об адвокатуре). В Кодексе профессиональной этики адвоката (далее также - КПЭА) (п. 2 ст. 13) этот запрет конкретизирован: адвокат, принявший в порядке назначения или по соглашению поручение на осуществление защиты по уголовному делу, не вправе отказаться от защиты, кроме случаев, указанных в законе, и должен выполнять обязанности защитника, включая при необходимости подготовку и подачу апелляционной жалобы на приговор суда. Еще одно исключение из запрета установлено Стандартом осуществления адвокатом защиты в уголовном судопроизвод- стве $^{9}$ : можно отказываться от защиты также в случаях, указанных в разъяснениях КЭС и утвержденных Советом ФПА.

Защита имеет место по уголовным делам в отношении подозреваемых и обвиняемых (ч. 1 ст. 49 УПК РФ), по делам об административных правонарушениях в отношении лица, против которого ведется производство по делу об административном правонарушении (ч. 1 ст. 25.5 КоАП РФ).

Недопустимость отказа от принятой на себя защиты подозреваемого, обвиняемого повторена в ч. 7 ст. 49 УПК РФ. В КоАП РФ такой нормы нет.

Недопустимость отказа от принятой на себя защиты рассматривается многими коллегами как своего рода социальная функция адвокатуры, ее публично-правовая обязанность, когда адвокат продолжает оказывать юридическую помощь доверителю, у которого возникли трудности материального характера и он не в состоянии продолжать оплачивать гонорар.

Между тем нередки иные мотивы клиента не выплачивать оговоренную сумму вознаграждения. Например, адвокат Е.В. Людиншина, описывая подобный случай из своей практики, указывает, что доверитель захотел «сэкономить», когда «общая картина для подсудимого стала положительной». При этом ей «сразу дали понять, что им [доверителю и его родителям] известно, что от принятого на себя поручения отказаться я не имею права и должна довести данное дело до конца» [2, c. 23]. Судебное разбирательство длилось около 1,5 лет. Оплата была произведена только за первые 6 месяцев. В итоге адвокату пришлось взыскивать гонорар в судебном порядке. Таким образом, адвокат год работал без оплаты, отказаться от защиты права не имел, взыскал гонорар через суд [2, с. 23]. То есть ни о каких материальных затруднениях у доверителя речь не шла, и я уверен, что это типичная ситуация.

Вторая ситуация выкристаллизовалась на практике буквально в последние пару месяцев, хотя нормативная база для нее существовала с момента принятия Закона об адвокатуре, то есть с 2002 года.

Согласно п. 2 ст. 20 этого закона адвокат вправе самостоятельно избирать форму 
адвокатского образования и место осуществления адвокатской деятельности. Однако п. 3 вводит исключение: в случаях, предусмотренных ст. 24 закона, адвокат осуществляет адвокатскую деятельность в юридической консультации. Пунктами 4 и 5 этой статьи предусмотрены обязанности совета адвокатской палаты утвердить: а) кандидатуры адвокатов и б) порядок их направления для работы в юридических консультациях.

Действующее регулирование вопросов функционирования юридических консультаций и работы адвокатов в них нечеткое, неясное, неопределенное, противоречит концепции адвокатской деятельности как свободной профессии. Сразу бросается в глаза формулировка «направление адвокатов для работы в юридической консультации». Как мы указывали выше, адвокат не состоит в трудовых отношениях ни со «своим» адвокатским образованием, ни с доверителем. «Авторы Закона об адвокатуре максимально старались избегать употребления слов “услуга" и (или) "работа"», - указывает В.В. Архипов [1, с. 38]. Это действительно так, поскольку им необходимо было решить двуединую задачу: 1) вывести адвокатскую деятельность из-под предпринимательской деятельности; 2) вывести адвоката из трудовых отношений.

С другой стороны, применительно к юридическим консультациям авторы закона пытались создать условия для принуждения в той или иной форме адвоката к работе в них, поскольку таковые создаются в отдаленных или депрессивных, то есть малопривлекательных для жизни и работы районах. Предполагалось, насколько я понимаю, что вопросы, кого из адвокатов и в какой форме направлять в юрконсультации, будут решаться региональными палатами путем внутреннего саморегулирования. Однако какого-либо определенного нормативного воплощения идея не получила, во всяком случае ни федеральная, ни региональные адвокатские палаты не создали корпоративных актов, регламентирующих порядок направления адвокатов в юридические консультации. Адвокатские палаты Удмуртской Республики, Республики Калмыкия и Свердловской области, имеющие наибольшее число юрконсультаций, направляют в них адвокатов исключительно по их желанию.
Однако 5 декабря 2018 г. Советом Палаты адвокатов Нижегородской области (далее - ПАНО) утверждено Положение о порядке направления адвокатов Палаты адвокатов Нижегородской области для работы в юридических консультациях ${ }^{10}$. В нем предусмотрено право Совета ПАНО направлять адвокатов для работы в юридической консультации на срок до 6 месяцев независимо от их согласия. Таким образом, предполагается принудительное (без их согласия) направление адвокатов для работы в юрконсультации в удаленные местности, за пределами их места проживания и осуществления деятельности.

\section{Международные нормы}

Запрет принудительного труда является общеправовым принципом, но в российском праве подробно разработан только в Трудовом кодексе РФ. Поэтому применение международных норм является приоритетным, поскольку в них нет строгой отраслевой привязки. Наше государство ратифицировало:

- Конвенцию Международной организации труда № 29 о принудительном или обязательном труде ${ }^{11}$;

- Конвенцию о защите прав человека и основных свобод ${ }^{12}$;

- Конвенцию Международной организации труда № 105 об упразднении принудительного труда ${ }^{13}$.

Определение термина «принудительный или обязательный труд» содержится в Конвенции № 29 и означает всякую работу или службу, требуемую от какого-либо лица под угрозой какого-либо наказания, для которой это лицо не предложило добровольно своих услуг. То есть это труд недобровольный и под угрозой наказания. Европейский суд по правам человека (далее - ЕСПЧ, Европейский суд) обращался к толкованию принудительного труда применительно к адвокатской деятельности, в частности в делах: № 08919/80 Van Der Mussele v. Belgium, постановление от 23.11.1983 ${ }^{14}$, и № 31950/06 Graziani-Weiss v. Austria, постановление от 18.10.2011 ${ }^{15}$. По обоим делам Европейский суд указал, что поскольку адвокаты знали о такой их обязанности (в определенных случаях осуществлять адвокатскую деятельность без оплаты), то 
B.A. Шавин. Принудительный труд адвоката: неизбежность конфликта в длительном уголовном процессе

они добровольно и предварительно дали на нее согласие, а потому такой труд не может рассматриваться как принудительный. Однако ЕСПЧ указал на необходимость соразмерности бремени (бесплатной работы), возложенного на заявителей. В указанных конкретных случаях Европейский суд пришел к выводу о соразмерности, поскольку заявители в обоих случаях не утверждали, что возложенная на них работа без оплаты была слишком длительной, сложной или затратной.

Схожие проблемы имеются и у американских адвокатов. Т. Нерони указывает, что «в отношении принудительного труда адвокатов или кандидатов в адвокатуру это проявляется, например, в принудительном назначении адвокатов судами с оплатой по тарифам в несколько раз ниже рыночных и в новом правиле лицензирования адвокатов в штате НьюЙорк, принятом в 2013 г. и вступившим в действие 1 января 2015 г., когда кандидат на лицензию адвоката должен бесплатно отработать на бедных 50 часов» [3, с. 3-4]. Она же указывает, что еще в 1984 г. суд указал: «...весьма обременительные назначения могут считаться неконституционной конфискацией, если они лишают адвокатов права зарабатывать на жизнь» [3, с. 3-4].

Констатируем, что выводы Европейского суда и американских судов по проблеме принудительного труда совпадают.

\section{Выводы и предложения}

Таким образом, проблема принудительного/обязательного труда адвоката существует как в нашей стране, так и за рубежом. Россия в плане регулирования этого вопроса находится в самом начале пути, в том числе из-за неясных формулировок Закона об адвокатуре. Также отсутствует корпоративное регулирование. В европейских странах и в США наметился единообразный подход к решению заявленного казуса, который заключается в том, что работу адвоката по назначению государства нельзя считать принудительным или обязательным трудом, даже если она осуществляется по сниженной оплате или вовсе без оплаты, поскольку адвокат заранее знал о такой возможности и дал на это согласие. Однако такая работа не должна быть непомерной, не должна лишать адвоката возможности выполнять оплачиваемую работу, не должна требовать от адвоката чрезмерных затрат времени, усилий, денежных средств. Иное будет являться нарушением ст. 4 Европейской конвенции о защите прав человека и основных свобод.

Полагаю правильными наработки ЕСПЧ по указанным выше делам, именно с учетом них и стоит развивать практику в корпоративных актах адвокатского сообщества.

\section{ПРИМЕЧАНИЯ}

1 Дискуссия «Основание участия адвоката в деле». URL: https://www.advgazeta.ru/diskussii/ osnovanie-uchastiya-advokata-v-dele/ (дата обращения: 11.01.2019).

2 Согласно ч. 1 ст. 37.1 Федерального закона от 31 мая 2002 г. № 63-Ф3 «Об адвокатской деятельности и адвокатуре в Российской Федерации» Комиссия по этике и стандартам является коллегиальным органом Федеральной палаты адвокатов, разрабатывающим стандарты оказания квалифицированной юридической помощи и другие стандарты адвокатской деятельности, дающим обязательные для всех адвокатских палат и адвокатов разъяснения по вопросам применения кодекса профессиональной этики адвоката, а также осуществляющим в соответствии с кодексом профессиональной этики адвоката и регламентом комиссии по этике и стандартам иные полномочия.

${ }^{3}$ Основания прекращения участия адвокатазащитника в уголовном деле. Часть 1: «Совет директоров». URL: https://youtu.be/Q339SgFRSBI? $\mathrm{t}=2578$ (дата обращения: 10.01.2019).

${ }^{4}$ Адвокат вправе, помимо адвокатской деятельности, вступать в трудовые отношения в качестве работника для осуществления научной, преподавательской и иной творческой деятельности (п. 1 ст. 2 Закона об адвокатуре), но это иная деятельность, и в настоящей статье она не рассматривается.

${ }^{5}$ Определение Конституционного суда РФ от 19.01.2011 № 48-O-O.

${ }^{6}$ Определение Конституционного суда РФ от 30.09.2004 № 322-O.

${ }^{7}$ Постановление Конституционного суда РФ от 14.02.2013 № 4-П.

${ }^{8}$ Определение Конституционного суда РФ от 05.02.2009 № 289-О-П.

9 Принят VIII Всероссийским съездом адвокатов 20.04.2017. URL: https://fparf.ru/documents/ congress_documents/standarty/49163/ (дата обращения: 10.12.2018).

${ }^{10}$ URL: http://apno.ru/component/wmartalpha/ docs/urkonsult?Itemid= (дата обращения: 22.01.2019). 
11 Ратифицирована Указом Президиума Верховного Совета СССР от 04.06.1956.

12 Ратифицирована Федеральным законом от 30.03.1998 № 54-Ф3.

13 Ратифицирована Федеральным законом № 35-ФЗ от 23.03.1998.

${ }^{14}$ URL: http://base.garant.ru/167321/ (дата обращения: 09.10.2018).

${ }^{15}$ URL: http://www.garant.ru/products/ipo/ prime/doc/70061518/ (дата обращения: 09.10.2018).

\section{СПИСОК ЛИТЕРАТУРЫ}

1. Архипов, В. В. Закон об адвокатской деятельности и адвокатуре и трудовое законодательство / В. В. Архипов // Адвокат. - 2009. - № 2. C. $32-44$.

2. Людиншина, Е. В. Стандарт как гарантия безошибочности / Е. В. Людиншина // Нижегородский адвокат. - 2018. - № 8 (190). - С. 22-24.

3. Нерони, Т. Принудительный труд адвокатов в США / Т. Нерони. - Электрон. текстовые дан. Режим доступа: https:/www.academia.edu/38278796/ $\%$ D $0 \% 9$ F \% D $1 \% 80 \%$ D $0 \%$ B $8 \%$ D $0 \%$ B D $\% \mathrm{D} 1 \% 83 \% \mathrm{D} 0 \% \mathrm{~B} 4 \% \mathrm{D} 0 \% \mathrm{~B} 8 \% \mathrm{D} 1 \% 82 \% \mathrm{D} 0 \% \mathrm{~B} 5 \% \mathrm{D} 0$ $\% \mathrm{BB} \% \mathrm{D} 1 \% 8 \mathrm{C} \% \mathrm{D} 0 \% \mathrm{BD} \% \mathrm{D} 1 \% 8 \mathrm{~B} \% \mathrm{D} 0 \% \mathrm{~B} 9 \% \mathrm{D} 1 \% 82$ $\% \mathrm{D} 1 \% 80 \% \mathrm{D} 1 \% 83 \% \mathrm{D} 0 \% \mathrm{~B} 4 \% \mathrm{DD} \% \mathrm{~B} 0 \% \mathrm{D} 0 \% \mathrm{~B} 4 \% \mathrm{D} 0 \%$ B2\%D0\%BE\%D0\%BA\%D0\%B0\%D1\%82\%D0\% BE\%D0\%B2_\%D0\%B2_\%D0\%A1\%D0\%A8\%D0\% 90? fbclid=IwAR3vMU3R21gjWf2SaqpvcwVZtV_v7
GyHBpv4qN8gVOcYJISN9FAXtyyN3pc (дата обращения: 04.02.2019). - Загл. с экрана.

4. Рогачев, Н. Д. Отказ от защиты в связи с невыплатой вознаграждения / Н. Д. Рогачев // Нижегородский адвокат. - 2018. - № 11-12 (193). - С. 6-9.

\section{REFERENCES}

1. Arkhipov V.V. Zakon ob advokatskoy deyatelnosti i advokature i trudovoe zakonodatelstvo [Law on Advocacy Activity and Advopcacy and Labor Legislation]. Advokat, 2009, no. 2, pp. 32-44.

2. Lyudinshina E.V. Standart kak garantiya bezoshibochnosti [Standard as a Guaranteeof Accuracy]. Nizhegorodskiy advokat, 2018, no. 8 (190), pp. 22-24.

3. Neroni T. Prinuditelnyy trud advokatov $v$ SShA [Compulsory Labour of Lawyers in the United States]. URL: https://www.academia.edu/38278796/ $\% \mathrm{D} 0 \% 9 \mathrm{~F} \% \mathrm{D} 1 \% 80 \% \mathrm{D} 0 \% \mathrm{~B} 8 \% \mathrm{D} 0 \% \mathrm{BD} \% \mathrm{D} 1 \% 83 \% \mathrm{D} 0 \%$ B4\%D0\%B8\%D1\%82\%D0\%B5\%D0\%BB\%D $1 \%$ $8 \mathrm{C} \% \mathrm{D} 0 \% \mathrm{BD} \% \mathrm{D} 1 \% 8 \mathrm{~B} \% \mathrm{D} 0 \% \mathrm{~B} 9 \% \mathrm{D} 1 \% 82 \% \mathrm{D} 1 \% 80 \%$ D1\%83\%D0\%B4_\%D0\%B0\%D0\%B4\%D0\%B2\%D0\%B E\%D0\%BA\%D0\%B0\%D1\%82\%D0\%BE\%D0\% B2 \%D0\%B2 \%D0\%A1\%D0\%A8\%D0\%90? fbclid $=\mathrm{Iw}$ AR3vMU3R2 1gjWf2SaqpvcwVZtV_v7GyHBpv4q N8gVOcYJISN9FAXtyyN3pc (acessed 4 February 2019).

4. Rogachev N.D. Otkaz ot zashchity v svyazi s nevyplatoy voznagrazhdeniya [Waiver of Defence due to Non-payment of Remuneration]. Nizhegorodskiy advokat, 2018, no. 11-12 (193), pp. 6-9.

\section{Information about the Author}

Vasiliy A. Shavin, Candidate of Sciences (Jurisprudence), Associate Professor, Department of Civil Law and Procedure, Lobachevsky State University of Nizhny Novgorod, Prosp. Gagarina, 23, 603950 Nizhny Novgorod, Russian Federation; Lawyer, Chamber of Lawyers of the Nizhny Novgorod Region, Bolshaya Pokrovskaya St., 25, 603005 Nizhny Novgorod, Russian Federation, vshavin@yandex.ru, https://orcid.org/0000-0002-2235-0496

\section{Информация об авторе}

Василий Анатольевич Шавин, кандидат юридических наук, доцент кафедры гражданского права и процесса, Нижегородский государственный университет им. Н.И. Лобачевского, просп. Гагарина, 23, 603950 г. Нижний Новгород, Российская Федерация; адвокат Палаты адвокатов Нижегородской области, ул. Большая Покровская, 25, 603005 г. Нижний Новгород, Российская Федерация, vshavin@yandex.ru, https://orcid.org/0000-0002-2235-0496 